\title{
Letter to the Editor The Silencing of Lived Experience: The Author's Response to a Review of Adoption Deception
}

It is interesting how personal views influence the way we think and write professionally about issues in child welfare. Tregeagle and Cheers' review (2016) of Adoption Deception: A personal and professional journey (Mackieson, 2015) is a good example of how deep beliefs can undermine consideration of the lived experience of another.

Adoption Deception synthesises my lifetime of personal experience as an adoptee with my 30-plus years of professional experience as a social worker, predominantly in child and family welfare - including child protection and intercountry adoption. Writing that book was my reflexive response to what I perceive as the relentless populist campaign to increase adoption rates in Australia without an adequately informed or balanced public discourse. Adoption Deception is thus pitched to a generic audience, not an academic one. Since writing Adoption Deception, I have commenced $\mathrm{PhD}$ research on Permanent Care Orders in Victoria - work that uses an academic discourse to engage a different audience.

When I wrote Adoption Deception, I wanted to share with people my experience of being an adult adoptee and a social worker wrestling with the sensitive and complex issues associated with adoption from both my personal and professional perspectives. It is clear to anyone reading the book that it is not intended to be an academic treatment of the subject, nor does it intend to dismiss other perspectives on adoption. It is the story of my own journey, as someone with lived experience of adoption. As with other stories of lived experience, it does not engage others' perceptions. Nor does it engage with current research or literature. Writing from lived experience released me from the constraints of academic expectations, leaving me free to address the fundamental issues associated with social work practice in adoption and ask confronting questions without needing to justify or answer them. It is particularly disappointing, therefore, that in their book review, Tregeagle and Cheers use a professional lens to dismiss my lived experience as an adult adopted under past adoption policies and practices. By implication, this also dismisses the right of others to express perspectives based on their own lived experience. Purposefully or unintentionally, the reviewers have misjudged the genre.
Many points either made or, more worryingly, ignored by Tregeagle and Cheers are problematic in their book review, suggesting a biased agenda. Whilst they acknowledge the importance of the child's voice in out-of-home care, they fail to consider children's rights and, in particular, that the practice of adoption, including Australia's open adoption, violates children's rights to the legal preservation of their genealogical identity and relations. They also disregard the substantive disagreement, internationally and domestically, with adoption-driven permanency planning hierarchies because adoption from out-of-home is inherently coercive. They argue that, in NSW, children in out-of-home care aged 12 years or more often express a wish to be adopted. Perhaps, this is unsurprising given the undoubted challenges experienced by the out-of-home care system in providing quality care for children. Tregeagle and Cheers' argument nevertheless fails to address issues of informed consent and the lifelong and intergenerational ramifications of adoption. Their conceptualisation of 'permanence' fails to grasp that research findings are nuanced and equivocal. Erroneously assuming that legal permanence is of greater importance to children and young people than relational permanence, they ignore the evidence that substitute parents, rather than children and young people, feel an enhanced sense of security through having an adoption order in place. In contrasting Adoption Deception with The Madness of Australian Child Protection: Why adoption will rescue Australia's underclass children (Sammut, 2015), they simplistically portray the contrasting viewpoints presented as extreme and binary in order to position a particular perspective which is unmistakably their own.

There are many things I could criticise about Tregeagle and Cheers' book review - not least of which is that their rather paternalistic comment that I take for granted 'the security offered by social recognition of belonging to a family and the importance of the life-long relationship' with my own adoptive parents suggests to me they think I should be more grateful. In fact, had I been placed on a Permanent Care Order I might have had a better chance of maintaining my biological family relationships and identity. A future challenge for out-of-home care is to provide children and 
young people with a good sense of belonging without undermining their genealogical identity and sense of self. Overall, however, Tregeagle and Cheers' attempt to silence my voice as someone with lived experience is by far the most disappointing and disconcerting aspect of their treatment of Adoption Deception. Their review clearly exposes a failure to grasp the fundamental nature and importance of lived experience and how it is expressed. It also illustrates how professionals can so easily undermine, either intentionally or unintentionally, the voices of those affected by professional decision making.

\section{References}

Mackieson, P. (2015). Adoption deception: A personal and professional journey. North Melbourne, Victoria, Australia: Spinifex Press.

Sammut, J. (2015). The madness of Australian child protection: Why adoption will rescue Australia's underclass children. Ballarat, Victoria, Australia: Connor Court Publishing.

Tregeagle, S., \& Cheers, D. (2016). Searching for truths in the debate about adoption from care. Children Australia, 41(3), 240-242. 